\title{
Joint, Soft Tissue and Wound Infections in Physiotherapy Patients from a Mobile Health Care Unit in a Refugee Camp in Northern Bosnia
}
A. Naddour (Annemarie Naddour)1,3, M. Jackulikova (Maria Jackulikova)1,3,

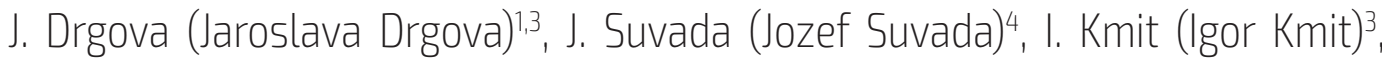 R. Hochman (Rastislav Hochman)1,3, V. Krcmery (Vladimir Krcmery)2,3, A. Liskova (Anna Liskova) ${ }^{3}$, J. Benca (Juraj Benca) ${ }^{3}$, R. Cauda (Roberto Cauda) ${ }^{5}$, M. Palenikova (Milica Palenikova)3, M. Olah (Michal Olah)3) M. Belovicova (Maria Belovicova)2,3, G. Herdics (Gyorgy Herdics) 2,3

${ }^{1}$ SEU Refugee Health Program Velika Kladusa, BH

Original Article

${ }^{2}$ UNHCR Refugee Camp Institute of Missiology St. John Paul 2, St. Elizabeth University Veria, GR

${ }^{3}$ Institute of Microbiology Med School Commenius Univesrsity

St. Lesley College University Hospital Nove Zamky University Hospital, St. John institute Pribram, CZ

Refugee Health Program, Health Post Hegyeshalom, HU

${ }^{4}$ UNHCR Camp II Dabayeh, Beirut, LB

${ }^{5}$ Inst of Inf \& Trop Dist, A Gemelli Hosp. Sacred Heart Univ. School of Medicine Rome IT

\section{E-mail address:}

tropicteam@gmail.com

\section{Reprint address:}

Annamaria Naddour

St John Paul II Inst of Missiology

Refugee Program Veroia, GR

Source: Clinical Social Work and Health Intervention

Volume: 9

Issue: 3

Pages: $19-23$

Cited references: 3

\section{Reviewers:}

Roberto Cauda - roberto.cauda@Unicatt.it

Peri Haj Ali - peri93@yahoo.com

\section{Key words:}

Physiotherapy. Wound. Joint. SSTI. Migrants and refugee health. 


\section{Publisher:}

International Society of Applied Preventive Medicine i-gap

CSWHI 2018; 9(3): 19 - 23; DOI 10.22359/cswhi_9_3_02 @ 2018 Clinical Social Work and Health Intervention

\section{Abstract:}

Background: This is a study about a refugee population of a "hidden" second wave of silent people who did not wait or could not wait for their asylum process to be completed on the Greek Island UNHCR camps or in those whose applications have been rejected (since they originated outside Syria and Iraq, and had little chance to get asylum in Greece, such as refugees from Afghanistan, Bangladesh, India, Pakistan, Iran).

Material and Methods: The aim of this survey was to detect etiology and describe our experience with treatment possibilities of physiotherapy related wound infections on skin and soft tissue in injured extremities, joints, bones, during long "food based" travel between Greece and North Bosnia $(800-1200 \mathrm{~km})$. About 500-800 refugees of armed conflicts from Syria (80\%), Iran, Afghanistan, Iraq and Pakistan (20\%) with zero attendance from North Africa have been observed in permanent transit and moved from July 7 to August 15, 2018.

Results: Within 144 patients who presented themselves in the Physiotherapy and Wound Unit of the Health Post in Velika Kladusa on the Bosnia/Croatia border, the majority had skin, soft tissue, joint and bone diseases, with majority presenting contaminated wounds after long walking, injuries, animal bites and accidents. Cultures were obtained in those who agreed and 51 cases were recorded and could be evaluated. 45 patients in field the Physiotherapy Ward Wound Unit had an invasive highly pathogenic bacterial pathogen including clostridium perfringens, MRSA, MSSA, P. aeruginosa, etc. In about 20\% these were mixed with fungal and in more than $50 \%$ with parasitic infection or mixed bacterial and or fungal pathogens Sarcoptes scabiei plus other organism.

Conclusion: In a non-refugee and non-migrant population in peace conditions, the majority of skin infections require minor debridement and local therapy with iodine, silver or alcohol based antiseptics. However in the immunocompromised population on long time of foot travel, systemic antibiotics, antifungals and anti-parasitic drugs may be required. Running title: Joint, skin and wound infections in long walking refugees on the Balkan Route.

\section{Introduction}

Refugee pathways in the Balkan Route changed in 2018 and the main flow blocked in Greece resulted to sublegal movement of small independent groups from Greece via Bosnia and Hercegovina directing via
Croatia to Schengen Space in Slovenia and Austria. This is a study on a refugee population of a "hidden" second wave of a silent group of those who did not wait or could not wait for asylum process to be completed 
on the Greek Island UNHCR camps or in those whom applications have been rejected (since they originated outside Syria and Iraq, and had little chance to get asylum in Greece, such as refugees from Afghanistan, Bangladesh, India, Pakistan, Iran). Exact number of this "silent" second Balkan "flow" is unknown since those small groups of 5-20 families move weeks, mainly early morning or night in woods and outside the roads to escape visibility of UN armed forces and local police in Bosnia.

\section{Patients and Methods}

The mobile refugee camp in Velika Kladusa belongs to several inconstant acute camps where those who are preparing to cross the Schengen border to Slovenia are seeking temporary shelter and rest before the final battle for freedom escaping from war. In Velika Kladusa, Bosnia and Herzegovina border to EU (Croatia and Slovenia).

The conditions in temporary camps are depressing, drinking water was used from a pipeline at a nearby football stadium or streams in the wood; no food supply; no assistance by international refugee based organizations therefore could be provided, such as UNHCR regular assistance; MSF support; WFP support; etc. Because of the predominant Muslim religion in Bosnia, the civil population was positive and supportive in finding cross boundary paths, small roads and also small food supplies. However, no health care could be provided apart from temporary visits of NGO Health Care Teams. For some days, one mobile Red Cross (IRC) Unit was observed to assist.

\section{Results and Discussion}

All but 6 , approximately. $80 \%$ of culture positive cases, 45 patients in Field Physiotherapy Ward Wound Unit had an invasive of highly pathogenic bacterial pathogen
- clostridium perfringens, MRSA, MSSA, P. aeruginosa, etc. In about $20 \%$ these were mixed with fungal and in more than $50 \%$ with parasitic infection or mixed bacterial and or fungal pathogens sucgh as sarcoptes scabiei plus other organism. Apart from serious pathogens such as clostricium, MRSA, MSSA S aureus, P.aeruginosa etc. less known pathogen infections of the human organism from the environment such as from water and soil, reflect in contamination from soil and animal bites (Kocuria species, Achromobacter spp, Pantoea spp, Clostridium spp, known to colonize oral cavity of dogs, in those reporting dog bites during police or border guards violence in migrants, reported in about 10 percent of those who were returned from Croatia, Serbia or Hungary).

Acute wound, joint, bone, skin and soft tissue infections in 51 of 144 patients were cultured and 31 swabs were positive for bacteria and 20 for ectoparasites (scabies secondary contaminated), in 10 cases mixed infection occurred (Tabl 1).

Concerning Therapy, in most cases with only superficial infections, local debridement of necrotic tissues, pus or fluid evacuation and local antiseptics of iodine or alcohol base were performed. In cases with animal bite or injury, tetanic toxoid was given muscularly. As we assumed that police dogs are vaccinated against rabies in all OECD member states, no anti-rabic prophylaxis was given. In addition, if an animal bite was reported, systemic antimicrobials, doxcycyline plus amoxicillin was given. In non-bite deep infections such as cellulitis, abscess, arthritis, osteomyelitis, co-trimoxazol with or without ciprofloxacin was administrated for 7-10 days.

When comparing the therapy practices in other studies on refugee and migrant health in Greece, Italy, Malta, Syria and Iraq, our 
finding was similar with environmental microbes firstly colonizing and after deeper immunosupression related to long travel by foot, sometimes $800-1200 \mathrm{~km}$ - we had a family walking $1,150 \mathrm{~km}$, those environmental organisms usually non-fermenting gram-negative soil and water contaminants, may cause severe coinfections in children and the elderly, since humans apart from animals and plants do not possess acquired or innate immunity to those organisms.

Assessing antimicrobial susceptibility in those environmentally originated bacteria, co-trimoxacol and doxycycline were the most active compounds, therefore we recommend in those exposed to animal-bite organisms, and soil-plant-water related gram-negative bacteria, the use of a combination of co-trimoxazol plus amoxicillin in children and potentially pregnant women, and in others co-trimoxazol in combination with ciprofloxacin, or doxycycline with ofloxacin, covering most organisms described from wounds of migrants refugees, animal bites, environmental contamination injuries. Second commonest ID was scabies., Therefore, antisarcoptic ointment is useful to decrease transmission due to swelling within a single patient or patient-to-patient (children among themselves) transmission of MRSA or MSSA. In about $20 \%$, when candida or other fungal skin infection is present, clotrimazole or fluconazole ointment is mandatory as local therapy as well. (3)

\section{Conclusion}

In a non-refugee and non-migrant population in peace conditions, a majority of skin infections require minor debridement and local therapy with iodine, silver or alcohol based antiseptics. However in this immunocompromised population aftern long time foot travel, systemic antibiotics antifungals and antiparasitic drugs were required. In about one third of patients combination therapy of all three types of agents - antibiotic, antifungal and antisarcoptoid antiparasitic agents locally, and about in $20 \%$ of systemic antibiotic therapy is required, in addition surgical debridement, or pus or fluid evacuation are mandatory as well with subsequent local and systemic remedial therapy. Physiotherapy is required in about 20-30 patients with relaxation techniques, massages, combined with hydrotherapy and local antireumatic ointments, in injured ankles, or exhausted extremities after long walk travel.

The best prevention of such type of injuries and SSTI are not medical or health measurements but ultimately a stop to current ongoing armed conflicts in Syria and Yemen, with country health infrastructure rehabilitation.

\section{Table 1}

Typical SSTI (wound) pathogens Total 34

C. faecalis 3

S. aureus 7

- MRSA 3

- MSSA 4

Pseudomonaceal 2

- Ps. Aeruginosa 2

Enterobacteriaceae 8

- E. agglomerans 4

- K. pneumoniae 2

C. perfringens 1

C. albicans 6

Soil / water / environment pathogens

Citrobacter braakii

Achromobacter xylosoxidans

Kocuria rosea

Acientobacter baumani

Stingomonas paucimobilis

Stenotrophomonas maltophila

Pseudomonas florescens 


\section{Fungal}

C. albicans

6

\section{Parasitic}

Sarcoptes scabiei

2. COUSINS S (2015) Syrian crisis: health experts say more can be done. Lancet. 2015; 385: 931-934.

3. MAHFOUD M, AL NAJJAR M, HAMZEH AR (2015) Multidrug resistance in Pseudomonas aeruginosa isolated from nosocomial respiratory and urinary infections in Aleppo, Syria. J Infect Developing Countries. 2015; 9: 210-213. 